\title{
An Analysis of Relations between Industrial Strategy and Enterprise Strategy
}

\author{
Yadong Zhu \\ School of Economics and Management, Hebei University of Technology, Tianjin, 300401,China, \\ Email: zydchina@139.com
}

Keywords: Industrial strategy; enterprise strategy; relation

\begin{abstract}
This paper analyzes relevant theories of the industrial strategy and enterprise strategy. It delves into how they interact with each other and what their differences are from the perspective of research subject, research purpose, environmental factors, and research methods for a better analysis of the industrial strategy.

\section{Introduction}

Entering into the 21st century, the economic globalization sweeping across the globe bridged the time and special gap between enterprises, which speeds up the globalization of market and thus makes enterprises worldwide increasingly integrated into a one unified market. Against this backdrop, the industrial and enterprise strategy is increasingly gaining prominence. It is often believed that there is no big difference between these two. However, in fact, much difference between them can be identified in theoretical research and in real practice. This paper conducts an analysis of the relationship between them on the theoretical basis of industrial economics and organization and enterprise strategic management.
\end{abstract}

\section{Industrial Strategy and Enterprise Strategy}

Enterprise strategy refers to management concept of one enterprise and its master planning for development objectives, methods and approaches so as to achieve long term steady growth in light of internal and external environment and available resources. Enterprise strategic management identifies long-term objectives for enterprises and refers to the process of allocating and arranging the strategic resources to reach those objectives.

Industrial strategy refers to the long-term policy measures taken by competent authority in charge of economic affairs in tackling major industrial problems with an aim for sustained development of local and state-level industry as a whole. To be specific, industrial strategy is the proposal and plan made by the local and state department of industrial management for guiding the sound and stable development of relevant industries based upon subjective and objective conditions through a better understanding of industrial trend and development laws.

Industry is an integrated system consisting of enterprises with common features [1]. The whole collection of industries constitutes the national economy with any particular industry being an integral part. Industrial development refers to the whole process from emergence, growth to industrial evolution. Hence the development strategy can be discussed in the following three layers. First, from the macro perspective, it is an industrial development strategy at state level. It is an instructive strategy guiding the development of local and national economy. Second, from the meso perspective, development strategy of one particular industry and local area is an exploration of its industrial development strategy, directions and tactics. A good case in point is the industrial planning formulated by state industrial department and industrial associations. Third, from the micro perspective, it refers to the development strategy of one particular enterprise, a strategy that identifies development objectives and allocates strategic resources so as to reach those objectives. The strategy of the upper level organization can provide guiding principles for lower level organizations, thus constitutes one of the external environment for lower level organizations to 
analyze. Similarly, the strategy of lower level organizations is the internal environment and element for upper level to conduct strategic analysis on. National economic development strategy provides guidance for the development directions of every industry and enterprises as they serve as an integral part of the national economy. Industrial strategy and policy sets out guiding principles for the formulation of enterprise strategy, directing the development of enterprise strategy. It is the external environment that enterprises need to take into account in conducting strategic analysis. One of the objectives of strategic management is to enhance the core competitiveness of the organization. As a basic element of the national economy, the competitiveness of enterprises determines the cutting edge and international competitiveness of one industry and one country. The strategy hierarchy is shown in the figure 1.

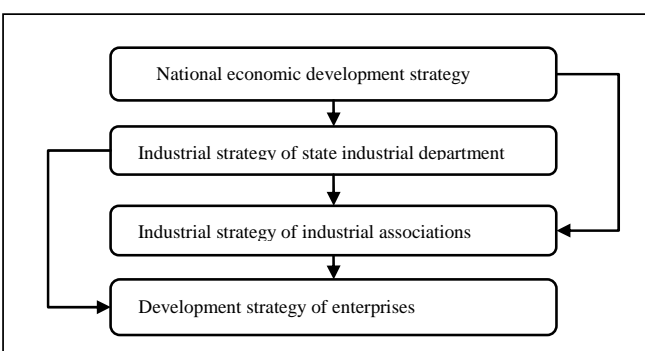

Fig.1. Strategy hierarchy

\section{Difference between Industrial Strategy and Enterprise Strategy}

\section{Difference in Research Subjects}

The research subjects of industrial strategy are government, state industrial department, and industrial associations etc. while the research subjects of enterprises are enterprises and entrepreneurs, etc.

\section{Difference in Research Content and Object of Study}

Industrial strategy and enterprise strategy refer to the relationship between the collectivity and the individuality in which the former matters much more than the latter combined. Enterprise strategy relates to each and every enterprise as a research individual. It advocates that each and every individual has its own unique problem with individualized competition as the analysis basis.

Industrial strategy gives more prominence to the industry with different development laws as a whole. Industrial research includes industrial organization, industrial structure, industrial correlation, industrial pattern, industrial development and industrial policy. Therefore industrial strategy must come up with a reasonable and master solution based on the industrial research of these issues.

\section{Difference in Research Purpose}

Such difference is determined by the roles of these two strategies in economic and social system. The focus of enterprise strategy lies in gaining cutting edge including the general profitability of the industry where the enterprise is located, in other words, industry attractiveness, and its comparative competitiveness as to whether it can improve itself so as to sustain long-term development in the industry.

The research purpose of industrial strategy is to gain a better understanding of changing features and laws of the industry and propose reasonable and effective solutions in order to improve competitiveness and cutting edge of core technologies. By so doing the leading position in industrial technologies can be secured.

\section{Different in Research Starting Point}

Enterprise strategy starts with profits and interests of enterprises themselves while industrial strategy starts with long term development of one country, one region or one industry as a whole.

\section{Difference in Environment}

The environmental factors of enterprise strategy include both external and internal environment. The former is usually twofold, namely macro-environment and task environment [2]. Macro-environment usually includes many factors such as politics and law, economy, population, social culture and science and technology. Task environment includes industrial competitiveness, attractiveness and the stakeholders of enterprises. The intra-industry competition factors mainly refer to intensity of competitive rivalry, bargaining power of suppliers, bargaining power of customers, threat of substitute products or services and threat of new competition as explained in the Michael Porter's Five Forces Model [3], which is supplemented by supplementary products factors. The enterprise stakeholders include local government, local community, creditors, 
shareholder or partner, employees and labor union, and trade associations, etc. The internal environment includes enterprise resources, capability and core competitiveness, etc.

The environment of industrial strategy also includes both external and internal environment, which exerts great influence on industry competitiveness and development. Despite similarities with enterprise strategy in external environment such as law, economy, science and culture, and in internal environment shaped by Porter's five forces, complementary industry and stakeholders, more environmental factors are involved in industry strategy with policy (industry policy and foreign investment policy), international cooperation(capital, technology and management, etc by multi-national companies and foreign direct investment), industrial foundation, market capacity, market demand, intensity of market competition and so on, which shaping external environment. The industrial internal environment is also influenced by natural condition, geographic position, source of raw material, public facility and the level of management and service [4].

The environmental factors influencing the formation of industrial strategy are much more complex than those of enterprise strategy. Environmental analysis model is illustrated in the figure 2. Judging from the
above analysis,
industrial environment is the important external environment of enterprise strategy analysis, and in turn enterprises serve as the internal environment of industrial strategy analysis.

The most important element in the profitability of enterprises lies in the profitability of the industry. As market is always in an ever changing process, the industry is accordingly undergoing cyclical

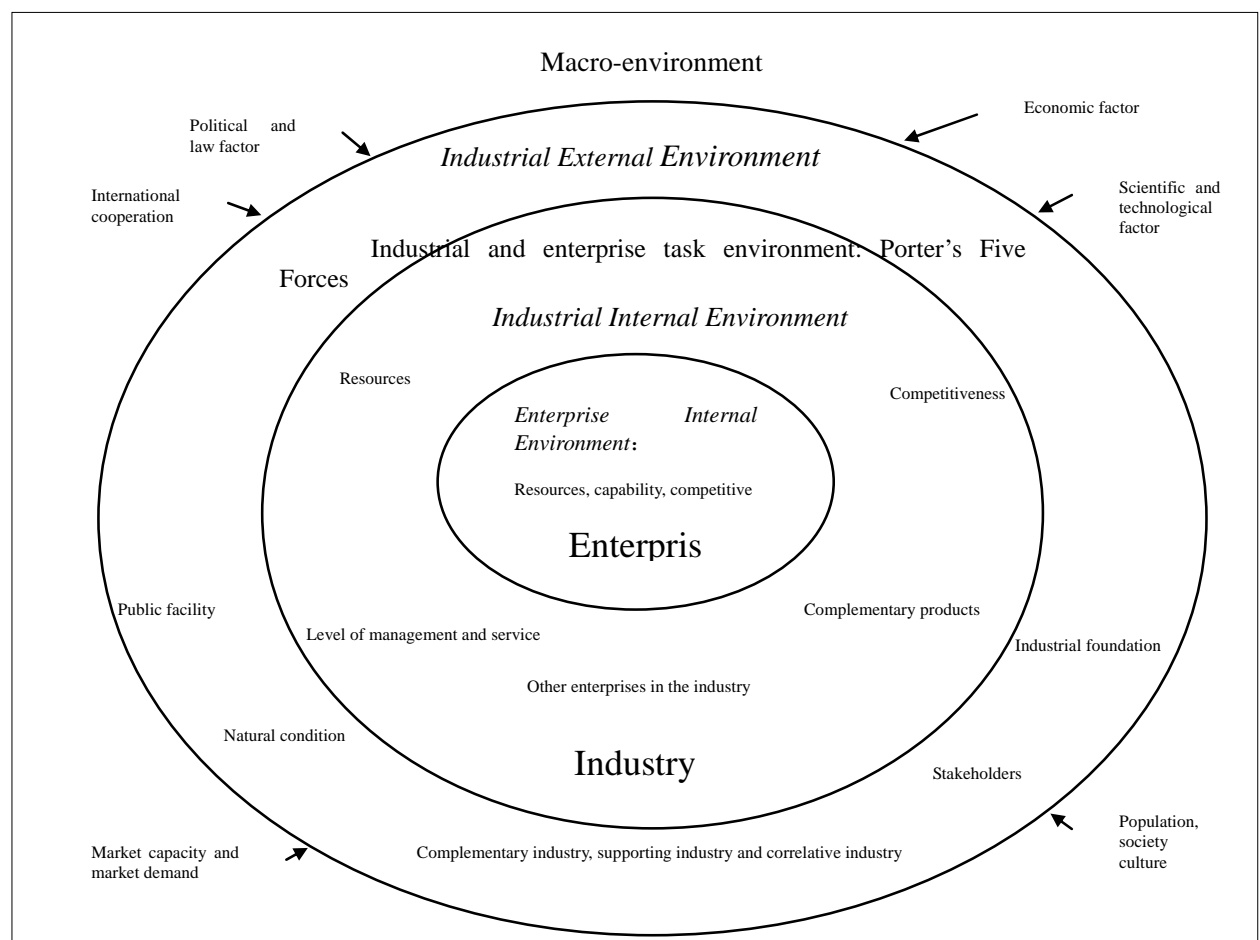

Fig. 2: Industrial and Enterprise Strategy Environment Analysis Model changes, thereby affecting the environment where enterprises survive and thrive and thus the profitability of enterprises.

In enterprise strategy management, the industrial environment where enterprises survive and thrive is of such critical significance to the competitiveness of enterprises as industrial strategy plays a deciding role in the enterprise strategy. At different phases of industrial development, enterprises tend to prefer different strategies [5]. Not only is the industrial strategy of significance to industry itself, but also exerts certain influence on the development of enterprises.

\section{Interplay Between Industrial Strategy and Enterprise Strategy}

Industrial strategy identifies scope for and provides guidance to business operation of enterprises. To formulate enterprise strategy one should first take the pulse of the industrial development trend. Enterprises must develop in accordance with the law of the whole industry, not the other way around. The essence of enterprise strategy lies in the mutual accommodation process of enterprise and industry.

\section{Industrial strategy influences the decision-making of enterprise strategy}

There are two core elements for enterprises to achieve success according to Porter's Competitive 
Strategy Theory. One is the attractiveness of industry where the enterprise is located; the other is the relative position of the enterprise in the industry. Industry itself is the key factor and important external environment deciding the competitiveness of enterprises. By making full use of its competitive strategy, enterprises can gain a favorable position in the industry and become profitable. Enterprises can institute effective enterprise strategies based on its unique technology and resources and on proper sizing up the industry it is in.

1) Industrial structure is the most important external environment for enterprises

Industrial external environment and the industry itself is the basic environment for the development of enterprises. These factors in most cases affect all enterprises in the industry. Industrial attractiveness constitutes the first and foremost factor deciding profitability of enterprises. Therefore competitive strategy of enterprises must first start by analyzing and understanding the law of industrial structure and industrial attractiveness.

Organizational structure will exert direct impact on enterprise strategy [6]. It may constrain the strategic choice and business activities of enterprises and it may tip the balance between the market demand and supply and may affect how much capital is invested in the industry. Industrial structure dictates industrial attractiveness and its profitability, thus reducing strategic opportunities and to some extent affecting the potential profitability of enterprises.

2) Changes of industrial development influence the choice of enterprises in adopting enterprise strategy

To formulate enterprise strategy, one needs to start with analysis of industrial structure. Industrial structure will keep changing in abreast with industrial development trend. The development of each and every industry has its own life cycle and displays different features on stages of introduction, growth, maturity and decline $[7,8]$. Industrial changes have fundamentally altered the competition condition within the industry, thus affecting the choice of enterprises in adopting strategies. Therefore enterprise strategy should also adjust itself in line with the industrial development trend.

3) Industrial policies influence strategic orientation of enterprises

Industrial policy is a component of the industrial strategy. It is a kind of government intervention into the shaping and development of the industry with an aim to achieving certain economic and social objectives. Industrial policy consists of industrial organization policy, industrial structure policy, industrial layout policy and industrial technology policy, all exerting great influence on enterprises. Such industrial policies as legal limitation, taxation, production restriction, price regulation and anti-monopoly will affect the strategic orientation and business activities. Industrial policies are the important external environment that one must take into account when devising development strategies.

\section{Strategic acts of enterprises affect the implementation and effectiveness of the industrial strategy}

As component of the industry, enterprises are the internal environment and important element for analysis of industrial strategy. They are the executor of industrial strategies and their strategic acts will affect industrial strategy in one way or another.

1) Strategic acts of enterprises may alter the strategic orientation of the industry

Market demand and technological advance are the driving force for the development of both enterprises and the whole industry. Enterprises are key to technological advance and such advance may lead to changes of market demand and thereby affects enterprise and industrial strategy. Innovative enterprise strategy may change the industrial cycle, and even create new industries and affect the development strategy of the whole industry. The strategy of emerging enterprises will guide a new direction for the development of the whole industry.

2) Enterprise activities affect the effectiveness of industrial strategy

Enterprises are the executor of industrial strategy. Enterprise activities decide the effectiveness of the industry. Market structure is decided by the number of enterprises, business scope and enterprise activities within the industry. Under different market structure and mechanism, different competition strategies devised by enterprises will determine different market behaviors. Such behaviors may have either positive or negative impact on the performance and efficiency of the 
whole industry. For instance, vicious competition within the industry will reduce the profit rate and undermine the development of enterprises. The business monopoly with the industry will also lead to declined international competitiveness of both enterprises and the whole industry.

In addition, in the implementation process of industrial strategy, the effectiveness of enterprise strategic adjustment on the micro level, attitude and how quick can it respond to changes will directly determine whether the industrial strategy can succeed.

3. Industrial competitiveness is the major indicator of comprehensive competitiveness of enterprises within the industry

To foster core competitive edge is the major target of strategic management. Competitiveness can be divided into the following three categories: national competitiveness, industrial competitiveness and enterprise competitiveness. Industrial competitiveness reflects national competitiveness and competitive edge and it is also the sum of enterprise competitiveness combined. The improved industrial competitiveness must be reliant on the overall improvement of competitiveness of enterprises within the industry. Industrial competition including competition among enterprises is embodied in the form of product competition, thus the industrial and enterprise competitiveness are the comprehensive indicator of the competitiveness of products. The core targets for both industrial strategy and enterprise strategy are to enhance competitiveness of products and enterprises.

\section{Conclusion}

Industrial strategy and enterprise strategy are of different strategic levels. They are complementing, influencing and mutually reinforcing each other. A clear line can be drawn between these two as the former studies on industrial development and the latter on enterprise competitiveness. Only when the relation is better understood can we gain an insight into the study of industrial strategy. This also holds practical importance for guiding the enterprise strategy management.

\section{References}

[1]Su Dongshui. Industrial Economics[M]. Beijing, HIGHER EDUCATION PRESS, 2000, PP.4-5

[2]Zhang Dongsheng, Li Yanshuang. Enterprise Strategy Management[M]. Beijing, China Machine Press, 2005, pp.81-88

[3]Michael E. Porter. The Competitive Advantage[M]. Beijing, Huaxia Publishing House, 1997, pp.4-10

[4]Michael E.Porter. The Competitive Advantage of Nations[M]. Beijing, CHINA CITIC PRESS, 2007, pp.64-116

[5]David Francas, Mirko Kremer, Stefan Minner, Markus Friese. Strategic process flexibility under lifecycle demand[J]. International Journal of Production Economics, 2009, (2), pp.427-440

[6]Wang Qun, Zhang Yang, Zheng Sheng'an. Study on Factors in Formulating Enterprise Strategy from the Perspective of Industrial Lifecycle [J]. Economic Research, 2008, (5), pp.48-52

[7]Ville Isoherranen, Pekka Kess, Kongkiti Phusavat, Binshan Lin. Strategy changes analysis using life cycle framework and strategy typology [J]. International journal of management and enterprise Development, 2011, 11(2/3/4)

[8]Liu Jianguo. Industrial Market Environment Characteristic and Enterprise Strategy Risk[J]. Technoeconomics \&Management Research, 2010, (6), PP.79-82 